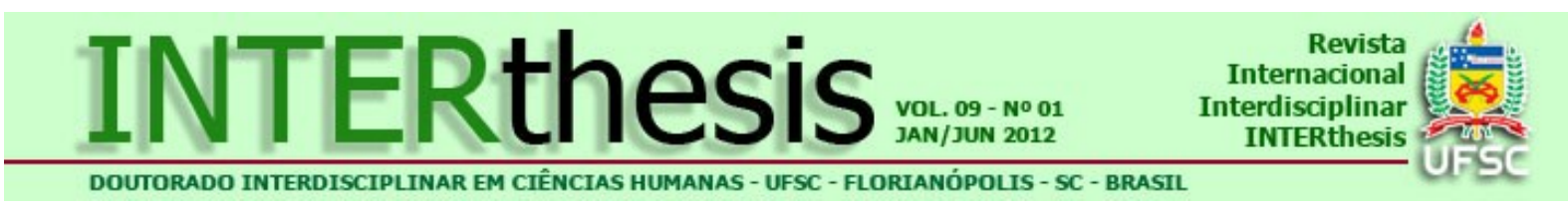

\title{
GESTAÇÕES NA ADOLESCÊNCIA: MULTIPLICIDADE DE EXPERIÊNCIAS EM UMA UNIDADE BÁSICA DE SAÚDE DE SANTA MARIA/RS ${ }^{1}$
}

\section{TEENAGE PREGNANCY: A MULTIPLICITY OF EXPERIENCES AT A BASIC HEALTH UNIT IN SANTA MARIA / RS}

\section{EMBARAZOS EN LA ADOLESCENCIA: MULTIPLICIDAD DE EXPERIENCIAS EN UNA UNIDAD BÁSICA DE SALUD DE SANTA MARIA / RS}

\author{
Naiana Dapieve Patias ${ }^{2}$ \\ Márcia Elisa Jager ${ }^{3}$ \\ Pascale Chechi Fiorin ${ }^{4}$ \\ Ana Cristina Garcia Dias ${ }^{5}$
}

\begin{abstract}
RESUMO
A gravidez na adolescência tem sido bastante investigada por pesquisadores, tanto do Brasil, como em outros países, principalmente a partir da década de 80 , quando esse fenômeno passou a ser visto como um problema de saúde pública. Assim, o presente trabalho tem como objetivo conhecer e refletir acerca do perfil de adolescentes gestantes usuárias de uma Unidade Básica de Saúde da cidade de Santa Maria - RS. Para isso foi utilizado um questionário contendo questões abertas e fechadas sobre sexualidade, contracepção, maternidade e projeto de vida. A partir de uma análise de conteúdo das informações, pode-se perceber uma multiplicidade de experiências relacionadas ao fenômeno da gestação na adolescência. Assim, destaca-se que é importante avaliar a história individual das adolescentes gestantes ao prestar atendimento as mesmas, pois a gestação e maternidade assumem
\end{abstract}

\footnotetext{
${ }^{1}$ Esta pesquisa foi desenvolvida pelo grupo de Pesquisa Cnpq: Avaliação e Intervenções no Desenvolvimento Humano (UFSM); contou com o financiamento do Edital MCT/CNPq/Mec/CAPES $n^{\circ}$ 02/2010 Ciências Humanas, Sociais e Sociais e Aplicadas (Processo 401135/2010-1)..

${ }^{2}$ Psicóloga, especialista em Criança e Adolescente em Situação de Risco pelo Centro Universitário Franciscano (UNIFRA), Mestre em Psicologia na Universidade Federal de Santa Maria (UFSM). Bolsista Capes. Doutoranda em Psicologia pela Universidade Federal do Rio Grande do Sul (UFRGS) E-mail: naipatias@hotmail.com

${ }^{3}$ Psicóloga, especialização (em curso) em Gestão de Pessoas e Marketing no Centro Universitário Franciscano (UNIFRA), Mestranda em Psicologia na Universidade Federal de Santa Maria (UFSM), Bolsista Capes E-mail: marciajager@yahoo.com.br

${ }^{4}$ Psicóloga, especialista em Clínica Psicanalítica Contemporânea (UNISC), Mestre em Psicologia na Universidade Federal de Santa Maria (UFSM), Bolsista Capes. E-mail: paca psi@yahoo.com.br

${ }^{5}$ Psicóloga, doutora em Psicologia Universidade de São Paulo (USP), Professora do Programa de Pós graduação em Psicologia na Universidade Federal de Santa Maria (UFSM). E-mail: anacristinagarciadias@gmail.com
}

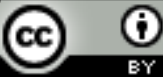


diferentes significados, dependendo da história familiar e do contexto sócio-cultural no qual se encontram inseridas.

Palavras-chave: Adolescência. Gravidez. Contracepção. Contexto. Perfil.

\begin{abstract}
:
Adolescent pregnancy has been widely investigated by researchers, both in Brazil and in other countries, mostly from the 80's on, when this phenomenon started to be faced as a public health problem. Thus, this study aims to evaluate and reflect on the profile of pregnant adolescents users of a Basic Health Unit of Santa Maria RS. We have used a questionnaire containing closed and open questions about sexuality, contraception, maternity and life project. From a content analysis of information, one can see a variety of experiences related to the phenomenon of teenage pregnancy. Thus, it is emphasized that it is important to assess the individual story of teenage pregnancy, because pregnancy and motherhood take on different meanings, depending on family history and socio-cultural context in which they are embedded.
\end{abstract}

Keywords: Adolescence. Pregnancy. Contraception. Context. Profile.

\title{
RESUMEN:
}

El embarazo en la adolescencia ha sido ampliamente investigado tanto en Brasil como en otros países, principalmente a partir de los años 80 , cuando esta situación pasó a ser vista como un problema de salud pública. Así, este estudio tiene como objetivo conocer y reflexionar sobre el perfil de las adolescentes embarazadas usuarias de una Unidad Básica de Salud de la ciudad de Santa María - RS. Para eso se utilizó un cuestionario con preguntas cerradas y abiertas sobre la sexualidad, la anticoncepción, la maternidad y el proyecto de vida. A partir de un análisis de contenido de las informaciones, se puede ver una variedad de experiencias relacionadas con la situación del embarazo en la adolescencia. Por lo tanto, se hace hincapié en que es importante evaluar la historia individual de las adolescentes embarazadas al atenderlas, porque el embarazo y la maternidad tienen diferentes significados, dependiendo de la historia de la familia y del contexto sociocultural en el que están inmersos.

Palabras clave: Adolescencia. Embarazo. Anticoncepción. Contexto. Perfil.

\section{INTRODUÇÃO}

A partir da transição demográfica brasileira iniciada na década de 60 , marcada pela redução significativa na taxa de fecundidade da mulher e pelo uso de métodos contraceptivos, a gestação na adolescência ganhou maior visibilidade. Anterior a esta data, a taxa de fecundidade girava em torno de seis filhos por mulher, porém, com o passar dos anos (de 1965 a 1995) essa proporção caiu para duas crianças para cada mulher. Assim, de acordo com o Censo realizado no ano 2000, a taxa de fecundidade da mulher brasileira vem decrescendo desde o ano de 1980 . Por exemplo, no Brasil, em 1980 observava-se uma taxa de fecundidade de 28,9\%, 
sendo que no ano de 2000 , foi constatada uma taxa de $26,3 \%$. No entanto, as taxas de fecundidade na adolescência, ao contrário das encontradas entre mulheres adultas, obtiveram um aumento. Por exemplo, das meninas de 15 a 19 anos, no ano de 1980 havia uma taxa de fecundidade de 9,1\%, já em 2000 observou-se um aumento significativo de $9,1 \%$ para $19,4 \%$ (IBGE, 2011).

Desta forma, considera-se que essas taxas são altas, especialmente porque a partir da década de 80 a gravidez na adolescência passou a ser vista como um problema de saúde pública por ocorrer fora do casamento, sendo investigada tanto por pesquisadores brasileiros como de outros países (DIAS; TEIXEIRA, 2010). Ainda, percebe-se que a gestação nesse período passa a ser vista como um problema, a partir das concepções atuais sobre o conceito de adolescência, que enfatizam que durante esse momento do desenvolvimento o indivíduo passa por alterações psíquicas e sociais e ainda não se encontraria pronto para o exercício da parentalidade. Nessa fase da vida, considera-se que o adolescente vive um período de preparação e maturação para assumir uma série de responsabilidades presentes na vida adulta, dentre elas a parentalidade, esperada socialmente como um evento da adultez (CABRAL, 2003).

Além das alterações psíquicas e sociais características da adolescência, ainda existem as alterações físicas e biológicas, que caracterizam a puberdade. Com ela, o corpo do adolescente desenvolve-se, podendo então desempenhar as funções de reprodução, de maneira plena. A vivência desta possibilidade, bem como o exercício da sexualidade depende da educação concedida pelos pais, do histórico familiar e das influências, práticas e significados vividos no contexto sociocultural no qual o adolescente está inserido (HEILBORN et al., 2002; XIMENES NETO et al., 2007). Assim, o exercício da sexualidade associado à capacidade reprodutiva é uma das principais mudanças que ocorre durante a adolescência, gerando uma série de conseqüências psicológicas, biológicas e sociais tanto para o adolescente como para as pessoas de seu entorno (PAPALIA; OLDS; FELDMAN, 2010).

De fato, durante esse período observam-se diferentes comportamentos nos adolescentes, principalmente em relação à sexualidade. Muitas adolescentes se envolvem em comportamentos sexuais de risco, o que se associa tanto a presença de DSTs, quanto a ocorrência de uma gestação, denominada por alguns pesquisadores, como "gestação precoce" (SANTOS; SCHOR, 2003). Diferentes 
fatores descritos na literatura estão associados à ocorrência da gravidez adolescente. Entre eles encontram-se: 1) história familiar de gestações na adolescência da própria mãe, irmãs, primas e tias; 2) o contexto socioeconômico e cultural na qual a adolescente está inserida (poucas perspectivas de escolarização e desenvolvimento profissional aliada à valorização do casamento e maternidade); 3) relações familiares (abusivas e falta de afeto que podem levar ao desejo da jovem sair desse ambiente hostil e formar uma família); 4) características próprias da adolescência (impulsisvidade, dificuldades em perceber as consequencias de seus comportamentos); 5) iniciação sexual precoce (quanto menor a idade da sexarca, maior o risco de não uso de métodos contraceptivos); 6) representações tradicionais de gênero e maternidade (desejar a maternidade pelo fato de que ela confere algum status social valorizado e pode ser representada como um passaporte para o mundo adulto; nas negociações sobre uso de métodos contraceptivos, as meninas que utilizam algum método sistemático podem ser consideradas "fáceis" ou não confiáveis) e 7) falta de informações sobre métodos contraceptivos (PATIAS; DIAS, 2011).

$O$ presente trabalho tem como objetivo conhecer o perfil de adolescentes gestantes usuárias de uma Unidade Básica de Saúde da cidade de Santa Maria RS, refletindo sobre os aspectos relativos ao contexto cultural dessas jovens, à vivência da sexualidade, ao uso de métodos contraceptivos e os projetos de vida futuros destas jovens. Pretende-se compreender como esses diferentes fatores podem estar contribuindo para a ocorrência da gestação adolescente.

\section{MÉTODO}

Para atingir os objetivos do estudo, foram convidadas, de forma aleatória, 10 adolescentes gestantes que aguardavam a realização de consultas pré-natais em uma Unidade Básica de Saúde da cidade de Santa Maria - RS. As adolescentes participantes tinham idades entre 13 e 19 anos e se encontravam entre $\circ 3^{\circ}$ e $8^{\circ}$ mês de gestação.

Para a coleta de informações foi desenvolvido, a partir da revisão de literatura sobre o tema, um questionário com questões abertas e fechadas, que possuía o objetivo de investigar dados sócio-demográficos, informações sobre sexualidade e 
métodos contraceptivos, crenças acerca de família e maternidade, bem como projetos futuro das adolescentes gestantes.

As questões abertas foram submetidas a uma análise de conteúdo temático categórica. Bardin (1977) descreve esta técnica como um conjunto de instrumentos metodológicos, que se aplica a diferentes conteúdos, sendo que o mesmo oscila entre o vigor da objetividade e a fecundidade da subjetividade. Desta forma, visando atingir os objetivos do estudo, as informações coletadas foram divididas em sete categorias, a saber: 1) Contexto da primeira relação sexual; 2) Uso de métodos contraceptivos; 3) informações sobre métodos contraceptivos; 4) Justificativas relacionadas ao não uso de contraceptivos ou uso inadequado; 5) Contexto sócioeconômico e cultural da gestante; 6) Situação ocupacional e projetos futuros; 7) Escolaridade. Já nas questões fechadas, foi realizado um levantamento de freqüências.

Esse trabalho foi aprovado pelo Comitê de Ética da Universidade Federal de Santa Maria (UFSM), RS, número do protocolo 23081.013700/2010-97. Da mesma forma, encontra-se de acordo com os preceitos éticos da Resolução 196/96, do Conselho Nacional de Saúde de pesquisa com seres humanos.

\section{RESULTADOS E DISCUSSÕES}

\section{Contexto da primeira relação sexual}

Essa categoria trata das informações sobre a iniciação das atividades sexuais das adolescentes gestantes. Procurou-se conhecer a idade e o contexto, no qual ocorreram as primeiras relações sexuais das entrevistadas.

Percebe-se que todas as participantes tiveram a primeira experiência sexual em uma relação estável de namoro. As idades da sexarca variaram de 13 a 17 anos, sendo que metade das meninas do estudo tiveram sua primeira relação sexual aos 15 anos de idade. A esse respeito, Ximenes Neto et al. (2007) destacam que a gestação adolescente está relacionada ao surgimento da menarca e ao desenvolvimento da primeira relação sexual de maneira precoce. De acordo com os autores, quanto mais cedo ocorre o início da atividade sexual, maiores são as chances de ocorrência da gravidez. Além disso, Xavier (2005) revela que quanto mais cedo a adolescente vive a primeira experiência sexual, menores são as 
chances de utilização de contraceptivos e, quando esses são usados, pode acontecer de maneira incorreta. No que se refere à questão da primeira relação sexual das adolescentes ter ocorrido em uma relação estável de namoro, percebese que, em geral, a primeira relação sexual e uma eventual gravidez durante a adolescência ocorrem em uma situação de namoro ou relacionamento estável (TORRES; MOREIRA, 2005).

\section{Uso de métodos contraceptivos}

Esta categoria congrega as informações sobre o uso de métodos contraceptivos, em termos de formas de contracepção conhecidas e freqüência da utilização, antes da gestação.

Observa-se que as adolescentes relataram conhecer e utilizar, principalmente, a camisinha e a pílula anticoncepcional, contudo, esses métodos eram utilizados de maneira descontínua. Em termos quantitativos encontramos que nove adolescentes referiram utilizar camisinha, nove participantes também disseram que utilizavam pílula anticoncepcional, duas participantes mencionaram fazer uso do coito interrompido como forma de prevenção à gestação, e uma adolescente usou a pílula do dia seguinte. O uso descontínuo desses métodos está relacionado à ocorrência da gestação.

Nove das dez adolescentes entrevistadas revelaram que usaram contraceptivos em sua primeira relação sexual, sendo a camisinha o método escolhido. Porém, em relações sexuais subseqüentes, o mesmo não ocorreu. Quatro adolescentes descreveram que sempre utilizaram a pílula anticoncepcional para prevenir a gestação; cinco indicaram que algumas vezes utilizavam e outras vezes não faziam o uso de métodos contraceptivos; apenas uma das adolescentes informou que nunca utilizou métodos contraceptivos nem na primeira relação sexual, nem nas subseqüentes. As quatro adolescentes que sempre usaram métodos contraceptivos, o fizeram de maneira inadequada, já que informam que ou se esqueceram de tomar algum dia, ou quando foi realizada a troca de pílula não o souberam realizar essa substituição de maneira adequada.

Guimarães, Vieira e Palmeira (2003) também encontraram que a pílula anticoncepcional e a camisinha são os métodos mais conhecidos pelas adolescentes. Os autores consideram que o grande conhecimento sobre a 
camisinha entre adolescentes e jovens se deve, provavelmente, às campanhas educativas que estão sendo realizadas pelo Programa DST/AIDS, centradas nesse método como forma de prevenção das doenças sexualmente transmissíveis. A popularização da pílula, na opinião dos mesmos, se deve ao desconhecimento de outros métodos anticoncepcionais existentes. Os autores lembram que a pílula anticoncepcional já foi muito discutida na mídia, em função das mudanças de comportamento sexual associados ao seu surgimento. Esses autores chamam a atenção para o fato de que os adolescentes necessitam de mais informações sobre métodos anticoncepcionais e sua forma de utilização. Da mesma forma, consideram importante que os adolescentes não apenas conheçam as diferentes opções de métodos contraceptivos existentes, mas que sejam discutidas, em campanhas sobre o tema, questões biopsicossociais associadas ao exercício da sexualidade durante a adolescência (GUIMARÃES; VIEIRA; PALMEIRA, 2003).

Alves e Lopes (2008), por sua vez, observam que mesmo que as adolescentes tenham conhecimentos sobre o uso de métodos contraceptivos, elas podem não os utilizar de maneira adequada e consistente, pois as informações recebidas são incompletas ou insuficientes para realização de uma prevenção adequada. Além disso, a falta de conhecimento acerca das representações que os adolescentes têm de si mesmos e do mundo que os cerca, bem como a presença pouco expressiva ou quase inexistente de programas de educação sexual, nas escolas contribuem para a não utilização de métodos contraceptivos ou uso inadequado dos mesmos (TORRES; MOREIRA, 2005).

\section{Informações sobre métodos contraceptivos}

Essa categoria discute elementos relacionados às informações das adolescentes gestantes sobre métodos contraceptivos. No questionário construído para este estudo foi perguntado através de questões abertas se as jovens haviam recebido informações sobre sexualidade e contracepção. Quando as jovens respondiam que sim, elas deviam falar o quanto receberam de informação (as alternativas eram: nenhuma informação, pouca informação, informação suficiente para evitar uma gestação). Realizou-se essa questão em relação as possíveis fontes de informação: mãe, pai, irmã(o)(s), tia (o)(s), amigo(a)(s), professor(s), internet, TV, 
revistas, médicos e outros profissionais da saúde. Desta forma, as jovens qualificavam o quanto recebiam de cada fonte de informação.

Percebe-se que a maioria das participantes afirmou possuir informações sobre o tema da sexualidade e contracepção. Porém, cinco das dez adolescentes revelam que receberam pouca informação, sendo essa insuficiente para evitar a ocorrência de uma gestação durante a adolescência. Destaca-se que uma adolescente afirmou que nunca recebeu informação sobre sexualidade e métodos contraceptivos. As demais participantes (quatro) responderam que receberam informação suficiente para evitar uma gestação, contudo outros fatores se encontram associados à ocorrência da gravidez. Assim destaca-se que a falta de conhecimento sobre sexualidade e contraceptivos ainda é um fator que contribui, de maneira importante, para ocorrência da gravidez, devendo este ser foco de atenção de programas de saúde e educação voltados ao público adolescente.

De acordo com Papalia, Olds e Feldman (2010) é difícil para o adolescente associar o sexo com a possibilidade de procriação e, assim, adotar um comportamento contraceptivo eficaz. Em nosso estudo, três adolescentes deram a seguinte como justificativa para a não utilização de contraceptiva ou uso infreqüente dos mesmos: "achava que a gravidez não fosse acontecer comigo", percebe-se por essa fala que as jovens tem dificuldades em antecipar as conseqüências de sua vida sexual ativa. Desta forma, percebe-se que o amadurecimento orgânico do adolescente ocorre antes do amadurecimento psíquico e emocional, podendo determinar a vivência da sexualidade de uma maneira imatura, que não Ihes possibilita a adoção de comportamentos preventivos às possíveis conseqüências negativas do exercício irresponsável da sexualidade (BERLOFI et al., 2006; PELLOSO; CARVALHO; VALESCCHI, 2004).

Do ponto de vista cognitivo, as adolescentes, principalmente as mais novas, têm dificuldades de prever as situações e as relações causais possíveis entre elas (PAPALIA; OLDS; FELDMAN, 2010). Parece ser difícil para as adolescentes pensarem nas conseqüências da realização do ato sexual sem proteção. As adolescentes podem apresentar pensamentos egocêntricos, associados às noções de não vulnerabilidade e existência única (fábula pessoal). Eles acreditam que a gravidez $\mathrm{e}$ as doenças sexualmente transmissíveis acontecem apenas com os outros, e não consigo mesmo, uma vez que se consideram "invencíveis" e "especiais" (AMAZARRAY et al., 1998; DADOORIAN, 2003; DIAS; TEIXEIRA, 2010). 
Além das informações precárias e das características próprias dos adolescentes que impedem ou dificultam o processamento das informações que possuem sobre comportamento contraceptivo, outras justificativas são utilizadas pelas adolescentes a fim de explicar a ocorrência da gestação. A próxima categoria trata desse tema.

Justificativas relacionadas ao não uso de contraceptivos ou seu uso inadequado

A partir das informações levantadas sobre o não uso ou uso inadequado pelas adolescentes de métodos contraceptivos, foram questionadas as razões relacionadas a esses comportamentos. Razões sociais e psicológicas foram descritas como motivos para não adoção de um comportamento contraceptivo mais efetivo, entre elas encontramos motivos como: 1) o medo que os pais descobrissem que estavam tendo relações sexuais; 2) acreditar que a pílula anticoncepcional engordava; 3 ) perceber que o uso de método contraceptivo na relação com o namorado poderia gerar desconfiança no mesmo em relação a sua honra, honestidade.

O medo dos pais tomarem conhecimento da vida sexual é uma das razões mais citadas por cinco, das dez adolescentes para o não uso de contraceptivos. Essa afirmação sugere que há uma falta de comunicação entre pais e filhos sobre sexualidade, ou mesmo uma repressão dos últimos no que se refere ao exercício da sexualidade dos filhos. Essa situação pode ser observada não apenas nesse estudo, mas também em outros realizados. Por exemplo, em um estudo concretizado por Dias (2001) com adolescentes grávidas, foi encontrado que os pais podem apresentar diferentes reações negativas tanto à gestação como à descoberta da vida sexual ativa da filha. Desta forma, condutas proibitivas e agressivas caracterizam o comportamento dos pais frente à descoberta da vida sexual da filha, sendo intensificadas na ocorrência de uma gestação na adolescência

Os pais parecem apresentar dificuldades em relação a sua própria sexualidade, o que dificulta o diálogo com os filhos. Essas dificuldades podem advir do fato de que a maioria dos pais podem não ter tido essas conversas com seus próprios pais, ou mesmo da dificuldade que os pais apresentam de aceitar que os seus filhos cresceram e podem exercer sua sexualidade de forma a procriar. Além disso, o tabu social que ainda paira sobre a sociedade acaba acarretando timidez, 
medo e vergonha em falar sobre questões que envolvam a sexualidade, isso ocorre tanto entre adolescentes quanto entre adultos, e entre adultos e adolescentes (DIAS; GOMES, 1999; BARBOSA; COSTA; VIEIRA, 2008; WITTER; GUIMARÃES, 2008). Desta forma, desconstruir o tabu que ainda paira quando se fala sobre sexualidade é o primeiro passo para minimizar os efeitos negativos da falta de comunicação entre pais e filhos sobre esse assunto (JAGER et al, 2011).

Desta forma, a dificuldade na comunicação e o aspecto proibitivo que normalmente os pais acabam tratando a sexualidade de seus filhos contribuem para que as adolescentes acabem não buscando os pais para conversar sobre sexualidade, pois temem que esses expressem sentimentos negativos, de desaprovação, ou mesmo punições físicas. Porém, quando os pais facilitam o diálogo, adotando uma postura de abertura e atenção àquilo que está sendo contado, os adolescentes se sentem compreendidos. Sentimentos de alívio, aceitação e pertencimento à família acabam surgindo, e a adolescente vivencia momentos de satisfação com os pais (SCHOLZE; DIAS, 2004). Nesse sentido, um aspecto que facilita a comunicação entre pais e filhos é a postura dos pais frente às conversas. Quando os pais adotam uma postura de abertura e escuta torna-se mais fácil o diálogo, sendo este desenvolvido com confiança, liberdade e amizade (WAGNER et al., 2005).

No que diz respeito a crença que "a pílula anticoncepcional engorda", encontrada nas entrevistas realizadas com as adolescentes gestantes, alguns estudos (TAQUETTE et al. 2005; XIMENES NETO et al., 2007) revelam que muitas adolescentes por possuírem poucas informações ou informações inadequadas sobre métodos contraceptivos, acabam acreditando em certos "mitos" contados a respeito do assunto. (TORRES; MOREIRA, 2005).

Já no que se refere ao terceiro motivo citado pelas participantes, autores afirmam que o receio do uso, o desconhecimento ou a impossibilidade de compra dos contraceptivos e as chantagens do parceiro que percebe a relação sexual desprotegida como prova de amor da adolescente são fatores que influenciam na não adoção de um comportamento contraceptivo adequado (DIAS; GOMES, 1999; DIAS; GOMES, 2000; TAQUETTE et al. 2005; XIMENES NETO et al., 2007). Além disso, em alguns contextos sociais a gravidez e maternidade nesse período de vida, podem ser desejadas e até mesmo percebidas com certa naturalidade (DADOORIAN, 2003). Esses aspectos serão discutidos na próxima categoria. 


\section{Contexto sócio-econômico e cultural}

Esta categoria discute sobre a importância do contexto sócio- econômico e cultural das adolescentes, relacionando-o com a ocorrência da gestação na adolescência. Desta forma, alguns elementos presentes no contexto político, cultural e social dessas adolescentes contribuem para a ocorrência da gravidez na adolescência.

Alguns estudos indicam que a gravidez durante a adolescência ocorre predominantemente, em um contexto no qual os jovens possuem menores oportunidades de vida em termos educacionais e/ou profissionais (DADOORIAN, 2003; HEILBORN et al., 2002; LIMA et al., 2004). Nesse contexto, a maternidade pode fazer parte de um "projeto de vida", que possibilita a inserção no mundo adulto da adolescente. Percebe-se que nas camadas populares, principalmente, o desejo pela maternidade, pode emergir precocemente na vida das jovens, que apresentam um projeto de vida no qual a maternidade é parte importante para a realização feminina (DADOORIAN, 2003). A gestação/maternidade pode possibilitar, em âmbito social, um reconhecimento importante à menina na medida em que ela consegue "ser alguém na vida" para o filho (PANTOJA, 2003; RANGEL; QUEIROZ, 2008). De fato, socialmente foi construída a concepção de gênero fortemente influenciada pela capacidade biológica de gestação da mulher. Dessa forma, historicamente coube a mulher o destino da maternidade como se fosse algo natural e "instintivo", sendo destinado ao homem o papel de provedor (ARIÈS, 1981).

De fato, questões contextuais são importantes de serem consideradas quando se analisa o fenômeno da gestação na adolescência. Neste estudo, encontramos apenas duas adolescentes que afirmaram que desejavam a gravidez, por isso engravidaram. Contudo, outras quatro participantes da pesquisa engravidaram após estarem morando com um companheiro. Ainda, outras jovens que engravidaram estavam em uma relação (namoro, morando junto) com o pai da criança, apenas uma gestante não quis falar sobre o pai da criança. Nesse sentido, percebe-se que a gestação surge dentro de um relacionamento estável, podendo inclusive fazer parte do planejamento do casal, que está constituindo um novo núcleo familiar. As adolescentes, ao serem questionados sobre seus projetos futuros, descreveram que desejavam constituir uma família com o namorado, pai do bebê. 
Essas informações encontradas vão ao encontro de dados apresentados por Dias e Aquino (2006). Esses autores observam que a vinda de filhos pode motivar a conjugalidade entre os adolescentes, o que, por sua vez, associa-se ao ingresso no mundo adulto, pois a união representa autonomia para o novo casal, frente às famílias de origem. Contudo, esses mesmos autores lembram que nem sempre isso ocorre, há situações em que o pai da criança não assume a gestação, assim a adolescente passa a ser mais dependente afetiva e financeiramente de sua família. Lembramos que em nosso estudo apenas uma das adolescentes entrevistadas relata não ter tido o apoio do pai da criança.

\section{Situação ocupacional e projetos futuros}

Essa categoria refere-se à situação ocupacional das adolescentes e seus projetos de vida. Tivemos apenas uma participante que trabalhava no momento da pesquisa, três afirmaram nunca ter trabalhado e seis disseram que trabalhavam antes da gestação, contudo no momento não estavam trabalhando. Suas ocupações eram: atendente de loja, de padaria ou/e lancheria, diarista e cuidadora de crianças. Quando questionadas a respeito de seus planos para o futuro, as adolescentes demonstraram mais de uma meta a seguir. Constata-se que todas desejavam trabalhar e, mais da metade, desejavam continuar estudando. Outros planos citados pelas adolescentes foram: ingressar em uma universidade, oficializar a união através do casamento, ter mais filhos, ter a própria casa, morar com o pai da criança (uma das jovens que não mora com o pai), fazer curso técnico e ser independente.

O desejo de trabalhar, que se sobressaiu como o principal projeto futuro, pode estar associado, segundo alguns autores, ao reconhecimento econômico e social, que 0 trabalho representa atualmente. $O$ trabalho está vinculado às idéias de satisfação, prazer, realização pessoal, melhora na auto-estima, formação de novos vínculos sociais, aprimoramento do conhecimento, maior desenvolvimento cognitivo e emocional, além de independência financeira e retorno material (SANTOS; MENDONÇA; ZANINI, 2010; LOSADA; ROCHA-COUTINHO, 2007).

Por outro lado, Dias (2009) observa que nas camadas populares, no que se refere ao projeto de escolarização e profissionalização de meninos e meninas, as meninas tendem a não ser incentivadas a prosseguir os estudos, uma vez que sua 
principal tarefa será cuidar dos filhos e da casa. Tarefa qual são culturalmente criadas para desenvolver. Isso será tratado na próxima categoria.

\section{Escolaridade}

Esta categoria visa refletir sobre a escolaridade, evasão e defasagem escolar observado nas adolescentes pesquisadas, relacionando-as com a situação de gestação na adolescência.

Seis adolescentes das dez entrevistadas responderam que não estudavam no momento da pesquisa. Três delas pararam de estudar devido à situação de gravidez e outras três por motivos não relacionados à gestação. Apenas uma das adolescentes entrevistadas, com 19 anos de idade, completou o ensino médio.

Ao se considerar a idade e a série escolar em que as participantes se encontravam no momento da pesquisa podemos observar que cinco adolescentes apresentaram defasagem escolar, pois possuíam idades superiores aquelas separadas para um indivíduo naquela série escolar. Além disso, a maioria delas descreveu algumas situações de reprovação escolar anteriores ao evento da gestação.

Madeira (1997) lembra que meninas grávidas deixam à escola por causa da gravidez, contudo, em muitos casos, a evasão escolar acontece antes da gestação. Essa autora indica que as adolescentes por ela pesquisadas possuíam pouco incentivo para o prosseguimento dos estudos. Esse fator associado às representações que as mesmas possuíam sobre família e maternidade podia levar ao desejo pela gestação. Segundo a autora, nas camadas populares as famílias tendem a não investir tanto nas meninas porque não esperam delas uma contribuição econômica, já que as meninas nessas camadas da população são criadas mais para casar, constituir família e ter filhos que para profissionalizar-se. Essa situação também foi observada em nosso estudo, uma adolescente pesquisada relata que teve que parar de estudar, pois precisava ajudar a mãe nos afazeres domésticos. 


\section{CONSIDERAÇÕES FINAIS}

De modo geral, percebe-se uma multiplicidade de experiências relacionadas ao fenômeno da gestação na adolescência. Nesse sentido, é importante avaliar diferentes fatores individuais, contextuais e mesmo históricos antes de pensar a gestação durante a adolescência como um problema de saúde pública. Esta parece assumir diferentes significados para os indivíduos envolvidos neste fenômeno.

As adolescentes entrevistadas demonstraram que quanto mais cedo é o início da atividade sexual, maiores são as chances de ocorrer uma gestação precoce. Apesar de demonstrarem possuir algum conhecimento sobre métodos contraceptivos, esse pode não ser suficiente para evitar a gestação. Os métodos mais conhecidos e esporadicamente utilizados pelas participantes foram: a camisinha e a pílula anticoncepcional. Diferentes razões estiveram associadas à não utilização ou uso esporádico desses métodos, entre elas encontramos motivos relacionados ao medo de os pais descobrirem sua iniciação sexual, a crença de que a pílula anticoncepcional pudesse engordar e o sentimento de que a não utilização de camisinha fosse uma prova de confiança ao seu companheiro.

Nesse sentido, observamos que programas voltados para saúde do adolescente devem considerar especialmente percepções, vivencias e valores dessa população. Da mesma forma, pode-se concluir que a informação que chega a estas adolescentes não está sendo clara o bastante, já que os dois últimos motivos citados por elas são apenas crenças, não retratando o que de fato o é. Além disso, esses dados preliminares indicam a necessidade de desenvolvimento de trabalhos para pais e mesmo profissionais de saúde, na medida em que o diálogo destes, com adolescentes, pode se apresentar difícil, portanto, inefetivo.

Outro fator importante de ser destacado é a questão do incentivo ao estudo e formação. É preciso considerar se os planos para o futuro, especialmente relacionados ao trabalho e estudos, estão disponíveis e são viáveis para os jovens de classes economicamente desfavorecidas. É possível que a gestação, durante a adolescência, esteja emergindo em um contexto de escassez de oportunidades, podendo oferecer meios, especialmente para a menina, na obtenção de reconhecimento social, através da maternidade (DADOORIAN, 2003). 


\section{REFERÊNCIAS}

ALVES, A.; LOPES, M. H. Conhecimento, atitude e prática do uso da pílula e preservativo entre adolescentes universitários. Revista Brasileira de Enfermagem, Brasília, v. 61, n. 1, p. 11-17, jan/fev. 2008.

AMAZARRAY, M. et al. A experiência de assumir a gestação na adolescência: um estudo fenomenológico. Psicologia Reflexão e Crítica, Porto Alegre, v.11, n. 13, p. 431-440, jun/jul. 1998.

ARIĖS, P. História social da criança e da família. 2. ed. Rio de Janeiro: LTC. 1981. $279 p$.

BARBOSA, S.; COSTA, P.; VIEIRA, N.. Estágios de mudança dos pais nas conversas com os filhos sobre prevenção HIVIAIDS. Revista Latino-Americana de Enfermagem, Ceará, v. 16, n. 6, p. 1019-1024, nov/dez. 2008.

BARDIN, L.. Análise de conteúdo. Lisboa: Edições 70, 1977.

BELO, M.; SILVA, J. L. Conhecimento, atitude e prática sobre métodos anticoncepcionais entre adolescentes gestantes. Revista Brasileira de Saúde Pública, São Paulo, v.3 8, n. 4, p.479-487, 2004.

BERLOFI, L. et al. Prevenção da reincidência de gravidez em adoles centes: efeitos de um Programa de Planejamento Familiar. Acta Paulista de Enfermagem, São Paulo, v.19, n. 2, p. 196-200, 2006.

BRASIL. Ministério da Saúde. Diretrizes e Normas Regulamentadoras de Pesquisa Envolvendo Seres Humanos. Resolução 196/96 do Conselho Nacional de Saúde. 1996. 19 p.

CABRAL, C. Contracepção e gravidez na adolescência na perspectiva de jovens pais de uma comunidade favelada do Rio de Janeiro. Cadernos de Saúde Pública, Rio de Janeiro, v. 19, n. 2, p. 283-292, 2003.

CECCONELLO, A.; DE ANTONI, C.; KOLLER, S. Práticas educativas, estilos parentais e abuso físico no contexto familiar. Psicologia em Estudo, Maringá, v. 8, n. esp., p. 45-54, 2003. 
DADOORIAN, D. Gravidez na adolescência: um novo olhar. Psicologia ciência e profissão, Rio de Janeiro, v. 23, n.1, p. 84-91, 2003.

DIAS, A. C. G. Análise das expectativas de jovens que vivenciaram a gravidez na juventude. In: LIBÓRIO, R., KOLLER, S. (org.). Adolescência e juventude: risco e proteção na realidade brasileira. São Paulo: Casa do Psicólogo, 2009. p.119-140.

DIAS, A. C. G. Conversas, em família, sobre sexualidade e gravidez na adolescência: a percepção de jovens gestantes. Psicologia: Reflexão e Crítica, Porto Alegre, v.13, n 1, p.109-125, 2000.

DIAS, A. C. G. Reações à gestação na adolescência. Psicólogo inFormação, São Paulo, v. 5, n. 5, p. 45-67, 2001.

DIAS, A. C. G.; GOMES, W. B. Conversas sobre sexualidade na família e gravidez na adolescência: a percepção dos pais. Estudos de Psicologia, Natal, v. 4, n. 1, p.79106, 1999.

DIAS, A. C. G.; TEIXEIRA, M. A. Gravidez na adolescência: um olhar sobre um fenômeno complexo. Paidéia, Ribeirão Preto, v. 45, n. 20, p. 123-131, jan/abr. 2010.

DIAS, A.; AQUINO, E. Maternidade e paternidade na adolescência: algumas constatações em três cidades do Brasil. Cadernos de Saúde Pública, Rio de Janeiro, v. 22, n. 7, p. 1447-1458, jul. 2006.

GODINHO, R et al. Adolescentes e grávidas: onde buscam apoio? Revista latinoamericana de Enfermagem, v. 8, n. 20, p.25-32, 2000.

GUIMARÃES, A.; VIEIRA, M.; PALMEIRA, J. Informações dos adolescentes sobre métodos anticoncepcionais. Revista Latino-americana de Enfermagem, v. 11, n. 3, p. 293-298, maio/jun. 2003.

HEILBORN, M. et al. Aproximações socioantropológicas sobre a gravidez na adolescência. Horizontes Antropológicos, Porto Alegre, v. 8, n. 17, p. 13-45, junho. 2002.

HOGA, L. Maternidade na adolescência em uma comunidade de baixa renda: experiências reveladas pela história oral. Revista Latino-Americana de Enfermagem, Ribeirão Preto, v.16, n. 2, p. 280-286, 2008. 
INSTITUTO BRASILEIRO DE GEOGRAFIA E ESTATÍSTICA. Taxa de fecundidade das mulheres brasileiras. Disponível em: <http://www.ibge.gov.br/home $>$. Acesso em: 05 mai. 2011.

JAGER, M.E et al. Práticas educativas parentais, sexualidade e gravidez na adolescência: Um estudo de caso. In: SEMINÁRIO CORPO, GÊNERO E SEXUALIDADE, 5, 2011 Rio Grande. Anais... Rio Grande: FURG, 2011.

LIMA, C. et al. Percepções e práticas de adolescentes grávidas e de familiares em relação à gestação. Revista Brasileira de saúde materno-infantil, Recife, v.4, n. 1, p. 71-83, jan/mar. 2004.

LOSADA, B.; ROCHA-COITINHO, M. L. Redefinindo o significado da atividade profissional para as mulheres: o caso das pequenas empresárias. Psicologia em Estudo, Maringá, v. 12, n. 3, p. 493-502, set/dez. 2007.

MADEIRA, F. Quem mandou nascer mulher? Estudos sobre crianças e adolescentes pobres no Brasil. Rio de Janeiro: Record /Rosa dos tempos, 1997.

MOREIRA, M.C.; SARRIERA, J.C. Satisfação e composição da rede de apoio social a gestantes adolescentes. Psicologia em Estudo, v. 13, n. 4, p. 781-789, 2008.

PANTOJA, A. "Ser alguém na vida": uma análise sócio-antropológica da gravidez/maternidade na adolescência, em Belém do Pará, Brasil. Cadernos Saúde pública, Rio de Janeiro, v. 19, n. 2, p. 335-343, 2003.

PAPALIA, D.; OLDS, S.; FELDMAN, R. Desenvolvimento Humano. 10. ed. Porto Alegre: AMGH. 2010. 928 p.

PATIAS, N. D.; DIAS, A. C. G. Fatores que tornam adolescentes vulneráveis a ocorrência de gestação. Adolescência \& Saúde, Rio de Janeiro, v. 8, n. 2, p. 40-45, 2011.

PELLOSO, S.; CARVALHO, M.; VALSECCHI, E. O vivenciar da gravidez na adolescência. Acta Scentiarum, Maringá, v. 24, n. 3, p. 775-781, 2002.

RANGEL, D. L. O.; QUEIROZ, A. B. A. A representação social das adolescentes sobre a gravidez nesta etapa da vida. Revista de enfermagem Esc Anna Nery, Rio de Janeiro, v. 12, n. 4, p. 780-788, 2008. 
SANTOS, M.; MENDONÇA, H.; ZANINI, D. Gênero e valores no trabalho. Paideia, Ribeirão Preto, v. 20, n. 45, p. 39-45, jan/abr. 2010.

SANTOS, S.; SCHOR, N. Vivências da maternidade na adolescência precoce.

Revista de Saúde Pública, v. 37, n. 1, p. 15-23, 2003.

SCHOLZE, M.; DIAS, A. C. G. A percepção dos adolescentes sobre suas conversas com os pais. Disciplinarum scientia, Santa Maria, v. 4, n. 1, p. 135-154, 2004.

TAQUETTE, S. et al. A relação entre as características sociais e comportamentos da adolescente e as doenças sexualmente transmissíveis. Revista Associação

Médica brasileira, São Paulo, v. 51, n. 3, p. 148-152, mai/jun. 2005.

TORRES, T.; MOREIRA, M. Gravidez na adolescência e processos educativos: sexualidade, sentimentos e projetos de vida. In: SIMPOSIO INTERNACIONAL DO ADOLESCENTE, 2, 2005, São Paulo. Anais... São Paulo, 2005.

WAGNER, A. et al. Compartilhar tarefas? Papéis e funções de pai e mãe na família contemporânea. Psicologia Teoria e Pesquisa, Porto Alegre, v. 21, n. 2, p. 181186, mai/ago. 2005.

WITTER, G.; GUIMARÃES, E. Percepções de adolescentes grávidas em relação a seus familiares e parceiros. Psicologia: ciência e profissão, Brasília, v. 28, n. 3, p. 548-557, set. 2008.

XAVIER, A. Comportamento sexual de risco na adolescência: aspectos familiares associados. 2005. 130 f. Dissertação (Mestrado em Psicologia do Desenvolvimento) - Universidade Federal do Rio Grande do Sul, Porto Alegre, 2005.

XIMENES NETO, F. et al. Gravidez na adolescência: motivos e percepções das adolescentes. Revista Brasileira de Enfermagem, Brasília, v. 60, n. 3, p. 279-285. maio/jun. 2007. 